\title{
Gene Expression and Synaptic Plasticity in the Auditory Forebrain of Songbirds
}

\author{
S. Ribeiro ${ }^{1,2,3}$ and C.V. Mello ${ }^{1}$ \\ ${ }^{1}$ Laboratory of Animal Behavior, New York, New York 10021, USA
}

The ZENK/zif-268 gene has been linked with neuronal plasticity. Curiously, although $Z E N K / z i f-268$ up-regulation in the mammalian hippocampus occurs in association with induction of long-term potentiation (LTP), its expression in the songbird's caudomedial neostriatum (NCM), an auditory brain region analogous to portions of the mammalian auditory cortex, has been detected in the context of long-lasting decreases in the neuronal response to song. Does this seeming paradox mean that $Z E N K / z i f-268$ serves different functions in different brain areas or across animal groups? Or could it be that inhibitory circuitry within the auditory pathway reverses the signal of LTP into habituation? We review here the studies on song-induced ZENK expression in NCM and discuss two alternative models of NCM that might reconcile the apparent discrepancies, as well as point to future lines of investigation.

Songbirds have been an attractive system in which to study the neuronal basis of learning because they learn their songs through imitation of an internalized auditory song model or template acquired from a father or tutor. The importance of longlasting song memories persists throughout adult life because they form the basis for individual recognition in the context of territorial defense and for mate selection during the breeding season. What is the neural basis for the formation of song memories?

The brain circuits that control song production ("the song system"), have been mapped and studied in considerable detail since the early 1970s (Nottebohm et al. 1976, 1982; Bottjer et al. 1984, 1989; Sohrabji et al. 1990; Scharff and Nottebohm 1991). Because these nuclei show evoked auditory responses in anesthetized birds (Margoliash 1983, 1986; Williams and Nottebohm 1985; Vicario and Nottebohm 1988; Doupe and Konishi 1991; Margoliash and Fortune 1992; Sutter and Margoliash 1994; Doupe 1997; Margoliash 1997), early investigation of the mechanisms of song perception tended to focus on the motor pathways related to the production of song. However,

${ }^{2}$ Present address: Department of Neurobiology, Duke University Medical Center, 101 Research Drive Durham, NC 27710, USA.

${ }^{3}$ Corresponding author.

E-MAIL ribeiro@neuro.duke.edu; FAX (919) 684-5435.

Article and publication are at www.learnmem.org/cgi/doi/ 10.1101/lm.34400. some recent studies on awake-behaving animals failed to reveal auditory responses in the same nuclei (Schmidt and Konishi 1998) and the question of whether song responses in the motor pathway play a key role in the acquisition of auditory memories is not yet settled. More recently, attention has significantly shifted toward brain pathways that are common to all birds and are more traditionally associated with auditory processing per se. As discussed below, this has been a consequence of studies employing gene-expression mapping in awake-behaving animals, followed up by neuroanatomical and electrophysiological investigations.

\section{Gene Induction Reveals Auditory Areas in the Songbird Brain}

The immediate-early gene (IEG) ZENK (aka zif-268 [Christy et al. 1988], egr-1 [Sukhatme et al. 1988], NGFI-A [Milbrandt 1987], and Krox-24 [Lemaire et al. 1988]) is rapidly and transiently induced in the brains of songbirds by song presentation (Mello et al. 1992). This induction is most prominent in two major forebrain subdivisions, the caudomedial neostriatum (NCM) and the caudomedial hyperstriatum ventrale (CMHV; Fig. 1A,B; Mello and Clayton 1994; ). ZENK induction by song in NCM has been observed in songbirds such as zebra finches (Mello et al. 1992), canaries (Mello and Clayton 1994), and song sparrows (Jarvis et al. 1997), as well as in nonoscine avian species such as parrots (Jarvis and Mello 2000) and hummingbirds (Jarvis et al. 2000). Several studies have expanded on the initial finding of song-induced brain-gene expression and have provided further suggestive evidence of an involvement of this response in the formation and processing of song auditory memories.

1. In addition to $Z E N K$, song presentation also induces the expression in NCM of the plasticity-related genes $c$-jun (Nastiuk et al. 1994) and BDNF (Li et al. 2000);

2. ZENK expression in NCM correlates positively with song novelty: It is very robust for a novel song, is completely abolished by sustained song repetitions, but recurs on introduction of a different song (Jarvis et al. 1995; Mello et al. 1995; Ribeiro et al. 1998; Ribeiro 2000);

3 . In canaries, analysis of $Z E N K$ expression patterns induced by a variety of natural stimuli shows that NCM

LEARNING \& MEMORY 7:235-243 @ 2000 by Cold Spring Harbor Laboratory Press ISSN1072-0502/00 \$5.00

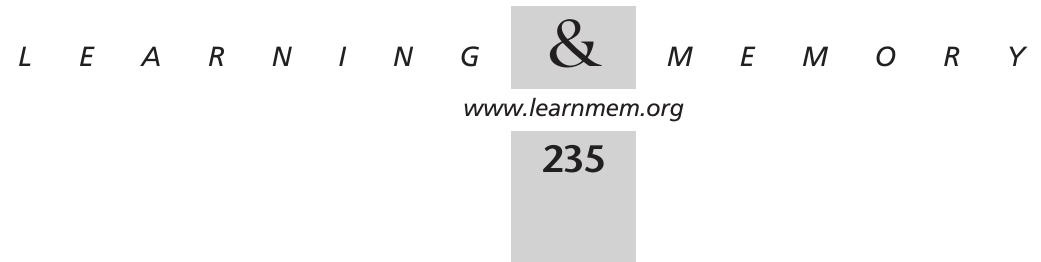



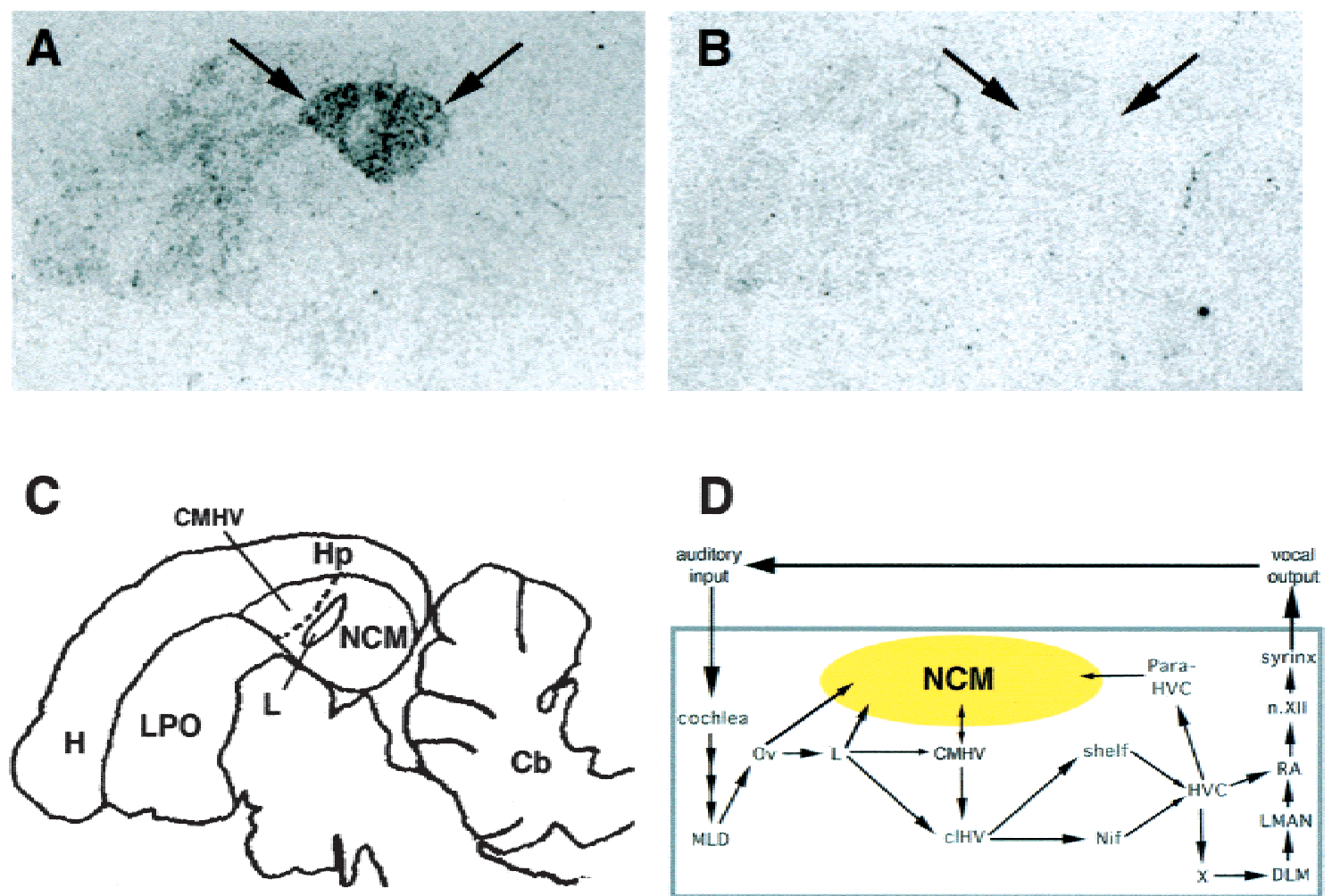

Figure 1 Song induces ZENK mRNA expression in auditory areas of the songbird forebrain. Upper panels show ZENK in situ hybridization autoradiographs of parasagittal caudomedial neostriatum (NCM) sections of zebra finches stimulated with song for 30 min $(A)$ or kept in silence for many hours $(B)$; notice the marked induction of ZENK by song in the caudomedial telencephalon, indicated by arrows. (C) Diagram of a parasagittal section at the plane shown in $A$ and $B ;(D)$ Schematic connectivity of the song sensorimotor continuum. Auditory information reaches the cochlea and ascends sequentially to the cochlear nuclei, the mesencephalon (Mld), the thalamus (Ov) and the primary telencephalic relay (field L). From there it takes parallel routes, which include NCM and CMHV. Through connections only partially shown here, auditory information reaches the high vocal center (HVC), a telencephalic nucleus that originates two parallel descending pathways that control the function of the syrinx and the production of song. Subdivision of field $L$ into fields L1, L2, and L3, as well as connections of field $\mathrm{L}$ with the shelf, are not represented. For panels $A-C$, dorsal is up, caudal is to the right. Abbreviations: $\mathrm{Cb}$, cerebellum; $\mathrm{CMHV}$, caudomedial hyperstriatum ventrale; $\mathrm{H}$, hyperstriatum; Hp, hippocampus; L, field L2a; LPO, lobus parolfactorius; NCM, caudomedial neostriatum; nucleus mesencephalicus lateralis pars dorsalis (Mld), nucleus ovoidalis (Ov); caudolateral hyperstriatum ventrale (CLHV); nucleus interfascialis (NIf) high vocal center (HVC); area X of the paraolfactory lobe (X); nucleus dorsolateralis anterior thalami, pars medialis (DLM); lateral magnocellular nucleus of the anterior neostriatum (LMAN); nucleus robustus arquistriatalis (RA); nucleus of the hypoglossal nerve (n.XII). Panels $A-C$ are adapted from Mello et al. (1992).

carries a well-ordered auditory map for the species-specific syllabic repertoire (Fig. 2A; Ribeiro et al. 1998; Ribeiro, 2000);

4. ZENK responses for natural songs or syllables in the NCM of canaries are consistently different from those elicited by other-species songs or artificial stimuli of very similar acoustic properties (Fig. 2B; Mello et al. 1992; Ribeiro et al 1998; Ribeiro 2000), suggesting that NCM might be involved in the categorization of natural song syllables;

5. ZENK expression in the NCM of adult male zebra finches correlates positively and significantly with the number of song elements copied from the tutor song during song acquisition (Bolhuis et al. 2000), suggesting that a memory trace of the songs heard early in life is retained in NCM.

\section{Neuroanatomical Studies}

Tract-tracing studies have shown that NCM receives inputs from the auditory thalamic nucleus ovoidalis and from the primary auditory telencephalic area field L (Fig. 1C). In addition, NCM is reciprocally connected with the adjacent CMHV, which is also a field-L target. NCM is also connected with regions that send inputs into the song motor control nucleus high vocal center (HVC) (Vates et al. 1996; Mello et al., 1998). Therefore, NCM represents a central auditory station within a complex circuitry that is likely to be involved in various aspects of song processing. The position occupied by NCM is comparable to that of the supragranular layers of the mammalian auditory cortex (Karten 1991, 1997) and potentially allows it to influence the access of auditory information to the song motor control system (Fig. 1C).

$$
\begin{array}{lllllllllllllll}
\text { L } & E & A & R & N & I & N & G & \mathcal{Z} & M & E & M & O & R & Y
\end{array}
$$




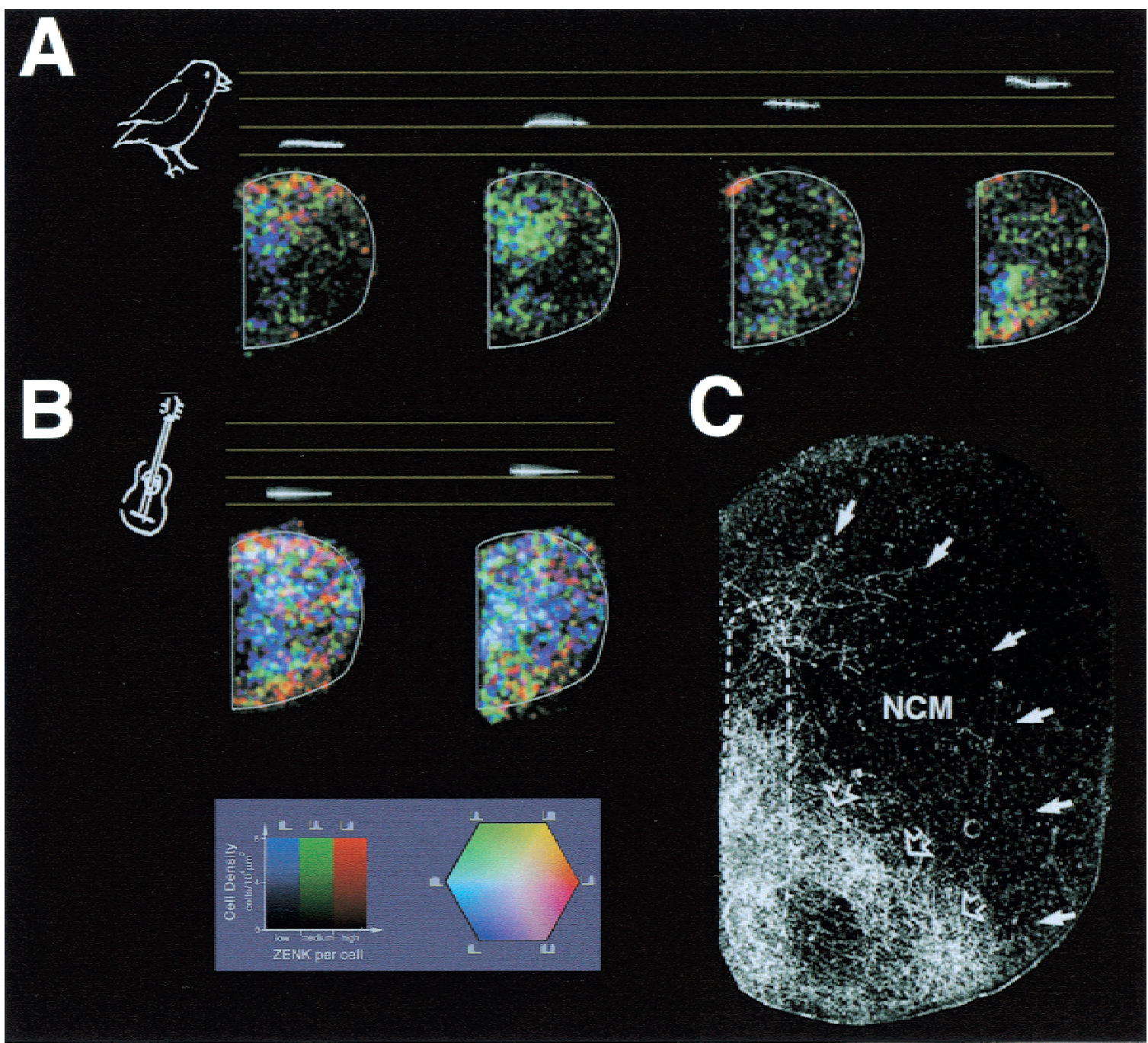

Figure 2 (A) Syllabic auditory representation in the canary brain. Panels show maps of ZENK-protein expression in the caudomedial neostriatum (NCM) resulting from the presentation of canary whistles at four different frequencies, as can be seen in the frequency vs. time plot (sonogram) of the stimuli depicted above the panels. Notice that clusters of whistle-responsive cells map along the dorsoventral axis as a function of whistle frequency; notice also that ZENK induction occurs mostly in the rostral portions of NCM (dorsal is up, caudal is to the right). (B) Tonotopy in NCM depends on natural features of the stimulus. Shown are maps of ZENK expression in response to harmonic-filtered guitar notes with the same frequencies as the whistles above (compare sonograms on top of each panel). Guitar notes generate unclustered low-ZENK responses throughout NCM, without a clear discrimination of stimulus frequency. The key on the bottom left depicts the color assignment to three populations of ZENK-labeled cells according to labeling intensity (blue, low protein; green, medium protein; and red, high protein). Brightness in the maps reflects cell density (in cells/104_m2); the key on the bottom right indicates how different relative proportions of the three cell populations result in various color mixtures (hues). The small icons in both graphs depict schematically the distributions of ZENK-labeling intensity that correspond to particular color mixtures. (C) Darkfield photomicrograph of a biocytin injection into field L2a, showing the pattern of anterograde labeling in NCM. Open arrows indicate the boundaries of the most intense labeling, which forms a band through rostral NCM. Solid arrows show the caudalmost limits of labeling. Panels $A$ and $B$ are adapted from Ribeiro et al. (1988); panel $C$ is adapted from Vates et al. (1996).

Although NCM's intrinsic microcircuitry still awaits to be unraveled in detail, some of the existing evidence suggests that NCM may be a heterogeneous structure, with different zones receiving different inputs. Most of the inputs from field $\mathrm{L}$ appear to arrive at the more rostral portions of the nucleus (Fig. 2C; Vates et al. 1996). In addition, as indicated by the placement of small anterograde tracer injec- tions, internal domains within NCM appear to be highly interconnected (Mello 1993).

\section{Electrophysiological Habituation}

NCM neurons fire robustly in response to novel auditory stimulation (Leppelsack and Vogt 1976; Muller and Leppelsack 1985; Chew et al. 1995,1996; Stripling et al. 1997), but

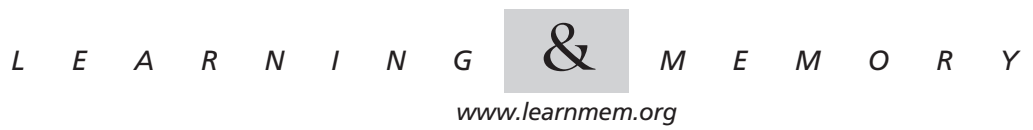


many of these neurons decrease their firing rates on repetition of the same stimulus. This phenomenon, termed "habituation" by analogy with the ethological term used for decrement of a behavior in response to a repeated stimulus, occurs in a long-lasting and stimulus-specific manner when same-species songs are used as stimuli (Fig. 3A; Chew et al. 1995, 1996; Stripling et al. 1997). Most of the habituating units are found in the caudalmost portions of NCM, whereas electrophysiological habituation in rostral NCM is negligible for any stimuli (Fig. 3B; Chew et al. 1995, 1996).

The decrease in neuronal firing to song in NCM is long lasting and can be divided into three phases. The first phase occurs within a few seconds and is characterized by a very rapid $15 \%-20 \%$ decrease in neuronal firing from the first to the second song presentation (Stripling et al. 1997). This is followed by a phase with a slower decline of responses, as reflected in the drop from $\sim 20 \%$ to $\sim 2 \%$ of firing-rate modulation per song bout. After $\sim 30 \mathrm{~min}$, the response reaches a stable asymptote at 30\%-60\% of the initial response, depending on the stimulation protocol used (Chew et al. 1995, 1996; Stripling et al. 1997). At present, the phenomenon of electrophysiological habituation to song in NCM is the best candidate to play a role in the formation of persistent song auditory memories in songbirds.

\section{Attention, Noradrenaline, and the Locus Coeruleus}

The mechanisms for stimulus-specific decrement of ZENK induction and of electrophysiological responses in NCM remain unknown, but it has been hypothesized that they reflect a decrease in attention (Mello et al. 1995). Indeed, studies of song associative learning in canaries have shown that $Z E N K$ expression in NCM after song presentation is modulated by attention mechanisms, as it can be increased by pairing songs to footshock, but is not increased when shock administration is not correlated with song occurrence (Jarvis et al. 1995). An important brain modulator of alertness and attention is the noradrenergic system. The main source of noradrenergic innervation in the brain is the locus coeruleus (LC; Kobayashi et al. 1975; Swanson and Hartman, 1975), a pontine nucleus present in all vertebrates that have been studied to date (Butler and Hodos 1996). In mammals, LC neurons burst at highest frequency when a novel stimulus is presented, and rapidly decrease their firing rate on sustained, nonnoxious stimulation (Aston-Jones and Bloom 1981a,b). Is it possible that the LC is also involved in the songbird brain's response to song? Can noradrenaline modulate birdsong memorization? Could that involve gene regulatory mechanisms? A strong indication that this might be so comes from the finding that an intact noradrenergic system is necessary for the sensory-induced expression of IEGs in the mammalian brain (Cirelli et al. 1996). This is of considerable interest because noradrenaline has been implicated in synaptic plasticity and in the neural control of learning in several systems (Everitt et al. 1983; Hopkins and Johnston 1984; Sullivan et al. 1989).

We began to address these questions by first showing that NCM receives a robust, noradrenergic innervation (Mello et al. 1998), which comes in close contact with $Z E N K$-positive, song-responsive neurons (Ribeiro et al. 1999). More recently, we found that ZENK expression in NCM can be abolished by systemic injections of noradrenergic antagonists of the $\alpha-1$ adrenoceptor subtype (Ribeiro 2000), indicating that noradrenaline is involved in the $Z E N K$ response to song. The results obtained so far suggest that the down-regulation of $Z E N K$ expression after repeated song stimulation may be at least partly related to a decreased firing of the LC. Given that the decrease in coerulear responses to novel stimuli occurs within a few seconds, it is plausible that the initial quick decrease of electrophysiological responses in NCM after song presentation stems
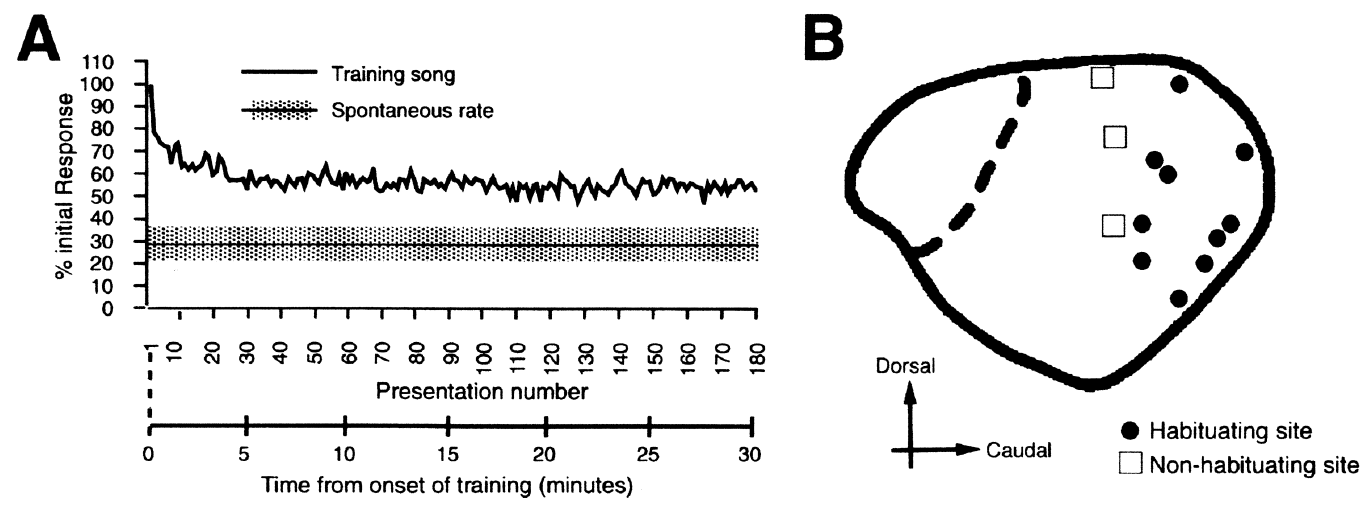

Figure $3(A)$ Electrophysiological habituation to song presentation by caudomedial neostriatum (NCM) single units. Notice that the largest drop in responsiveness occurs between the first and the second song presentations (adapted from Stripling et al. 1997). (B) Electrophysiological habituation seems to be most conspicuous in the caudalmost portions of NCM, whereas rostral NCM sites tend to be nonhabituating (adapted from Chew et al. 1995).

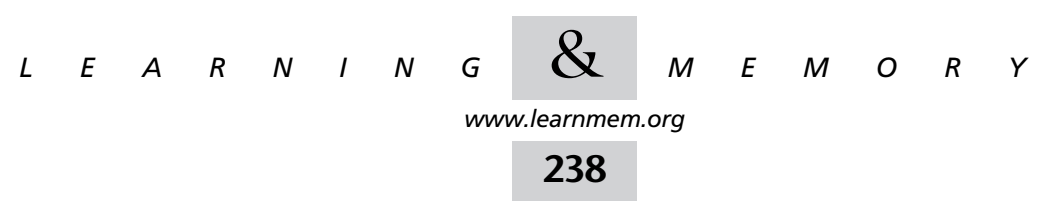




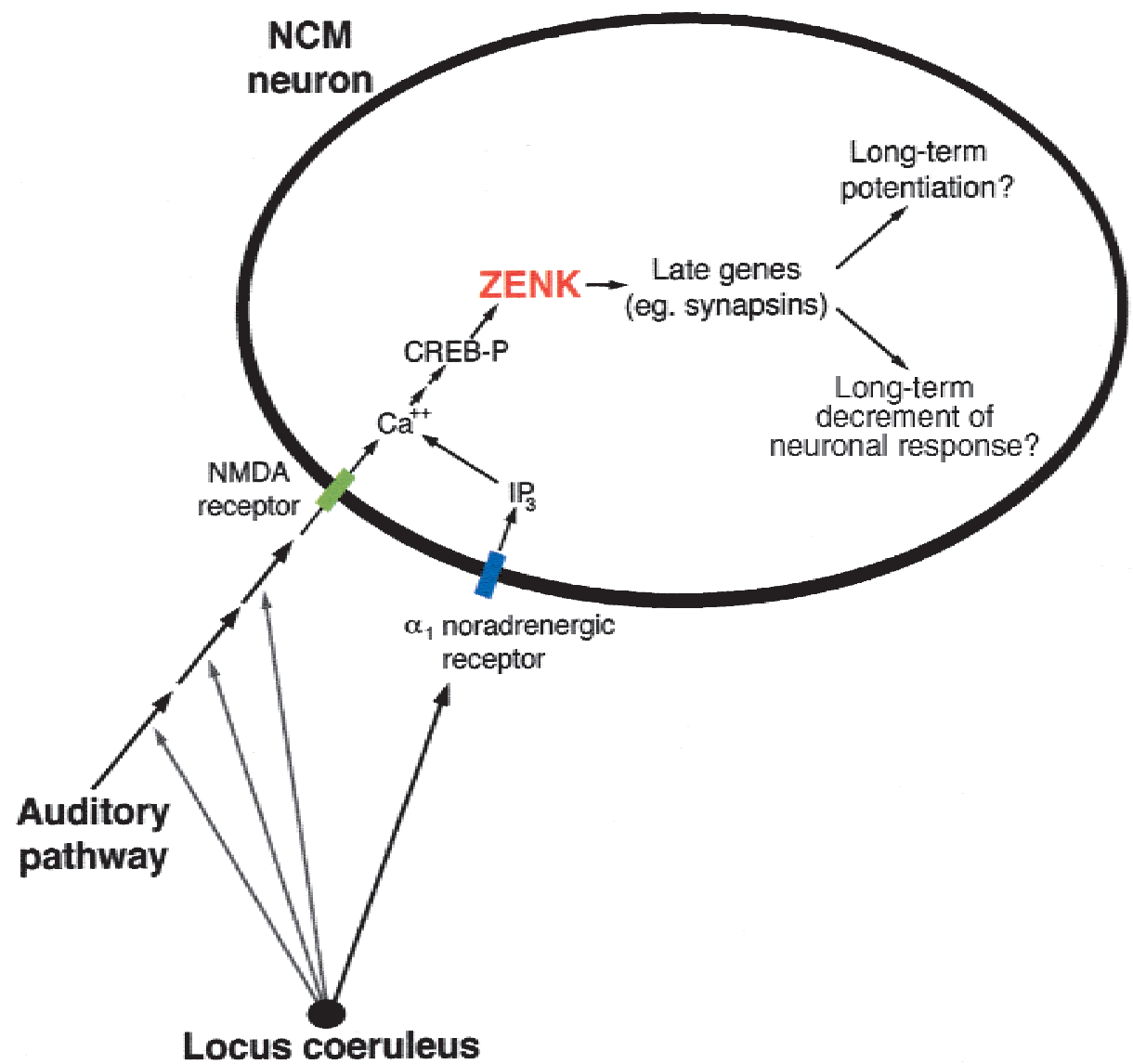

Figure 4 The existing data indicate that ZENK expression in caudomedial neostriatum (NCM) neurons depends on inputs from the auditory pathway as well as noradrenergic modulation by the locus coeruleus (LC). The grey arrows departing from the LC indicate that noradrenergic action on the auditory pathway might occur at any level prior to NCM. Directly or indirectly, it is likely that noradrenaline in NCM through $\alpha-1$ adrenoceptors (Ribeiro et al. 1999; Ribeiro 2000). Presumably, the $N$-methyl-D-aspartate and $\alpha-1$ adrenoceptor pathways of activation converge at the level of calcium signaling, leading to CREB phosphorylation and ZENK induction. ZENK is a transcription factor whose DNA-binding site is present in the promoters of several genes (possibly hundreds), and it has been shown to promote the in vitro transcription of synapsins I and II. At present, it is unclear whether ZENK expression in NCM is linked to long-term synaptic potentiation or to the decrement of electrophysiological responses.

from a steep decrease of $\alpha-1$ adrenergic modulation (Fig. 4). This view implies that maximum noradrenergic modulation occurs in the first song presentation, which is consistent with the fact that nearly half of the maximum ZENK response in NCM (as measured by the number of immunopositive cells) can be obtained with the presentation of a single songbout (Kruse et al. 2000). Because all the stimulation protocols used in the studies described included silence intervals between songs, it is probable that the LC becomes repeatedly reset during stimulation, what might be related to the paced dynamics of the second phase of habituation in NCM. Finally, the interpretation proposed above implies that noradrenergic modulation is almost completely interrupted after $\sim 30 \mathrm{~min}$ of song presentation, which might explain the decline of ZENK expression rates around the same time (Mello et al. 1992; Mello and Clayton 1995; Mello and Ribeiro 1998).

\section{ZENK and Long-Term Synaptic Plasticity: Tentative Models of NCM Function}

What is the function of ZENK and what are the consequences of its induction by song in NCM? Based on research performed in different systems, ZENK appears to be part of a molecular cascade leading from extracellular stimulation to changes in neuronal gene expression and long-lasting modifications in synaptic efficacy. Such a cascade includes sustained neuronal depolarization, $N$-methyl-D-aspartate (NMDA)-receptor activation and channel opening, calciumsignaling pathways, PKA activation, CREB phosphorylation, and induction of IEGs as well as late-target genes (Goelet et al. 1986; Cole et al. 1989,1990; Sheng and Greenberg 1990; Sheng et al. 1990). The $Z E N K$ gene encodes a zinc finger transcriptional regulator (Christy et al. 1988), and exerts its action by controlling expression levels of downstream genes that contain $Z E N K$-binding motifs in their promoters

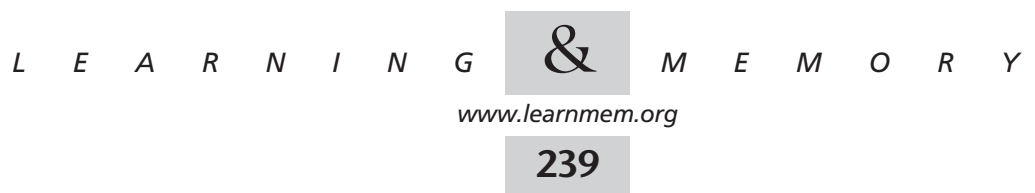


(Christy and Nathans 1989; Gupta et al. 1991). In particular, ZENK has been shown to directly regulate the expression of synapsins I and II (Thiel et al. 1994; Petersohn et al. 1995), which are essential components of synaptic complexes (Fig. 4).

In the rat hippocampus, $Z E N K$ induction has been clearly linked to the induction of long-term potentiation (LTP; Cole et al. 1989; Wisden et al. 1990; Abraham et al. 1993; Roberts et al. 1996). Even though some controversy persists (Shors and Matzel 1997), LTP is largely believed to play an important role in the formation of long-term memories. The fact that LTP is abolished by local application of inhibitors of RNA and protein synthesis (Nguyen et al. 1994) shows that the activation of transcriptional regulators is a necessary step for the long-term maintenance of synaptic potentiation. To this date, ZENK is the only known IEG whose electrophysiological-induction profile tightly matches that of LTP (Worley et al. 1993).

Is the association between $Z E N K$ expression and LTP a general one? The results obtained in songbirds raise the possibility that this might not be so. As discussed above, the prevailing consequence of repeated song presentation is a decrement in the activity of song-responsive NCM neurons. Local injections of inhibitors of RNA and protein synthesis have shown that the long-term maintenance of this habituation-like phenomenon depends on local transcription and translation (Chew et al. 1995). These findings suggest that the long-lasting modification of neuronal responses in NCM depends on a gene-expression program triggered by song presentation. As repeated presentation of a single, conspecific song to zebra finches results in $Z E N K$ expression in $\geq 40 \%-45 \%$ of the neuronal cell population within NCM (Mello et al. 1995), it seems plausible that ZENK induction in NCM is associated to long-lasting neuronal habituation, and not potentiation. In this case, the consequence of activation of the genes downstream to ZENK would be the long-term maintenance of decreased responsiveness of NCM neurons to song (Fig. 4). The difficulty with this model, in comparison with the studies in the rat hippocampus, is that it implies that induction of the ZENK gene can be associated with opposite directions of neurophysiological plasticity in different vertebrate species and/or brain areas.

As an alternative, one could postulate that the association between $Z E N K$ induction and LTP is conserved across different classes of animals and/or neuroanatomical structures. In that case, one should expect synaptic potentiation to occur in NCM as a result of song presentation. This would imply that $Z E N K$ induction and electrophysiological habituation occur in different subpopulations of NCM neurons. In support of this view is the observation that although the decrement in electrophysiological activity occurs predominantly in caudal NCM (Fig. 3B), ZENK expression by natural song stimuli is mainly located in the rostral portions of NCM (Fig. 2A). The notion of a functional compartmentalization of NCM into rostral and caudal domains is supported by the neuroanatomical data available to date (Vates et al. 1996). Against this hypothesis is the fact that evidence for neuronal potentiation of NCM neurons in response to song is lacking, but one might claim that a direct search for LTP-like phenomena in rostral NCM is yet to be attempted.

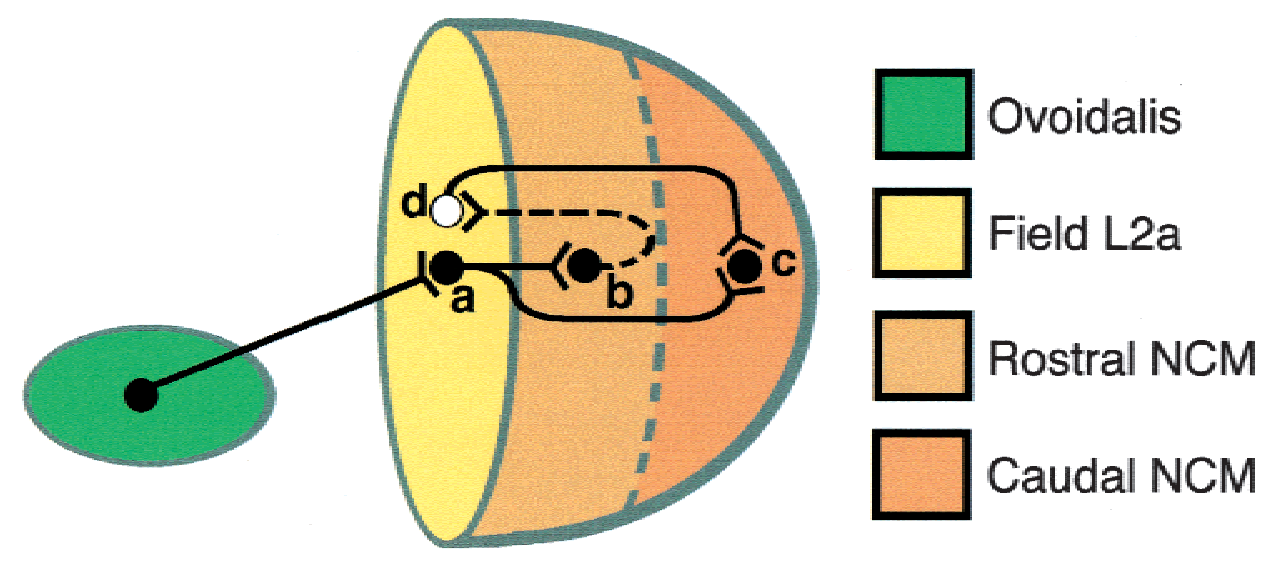

Figure 5 The model divides caudomedial neostriatum (NCM) into two bands of neurons characterized by distinct connectivity with a field L2a inhibitory loop. A putative projection from NCM to field L2a is indicated by the dashed arrow. The excitatory neuron A projects to two different neurons of NCM, B and C, in the rostral and caudal bands of NCM, respectively. Neuron B, in addition to its feedforward projection, feeds back onto the GABAergic neuron D in field L2a, which sends inputs to neuron C and to adjacent field L2a type-A cells. Neuron C integrates signals from B and D. Assuming that ZENK is related to long-term potentiation (LTP) in birds (Bradley et al. 1993,1995; Shapiro and Wieraszko 1996; Livingston and Mooney 1997) as it is in mammals, the high levels of ZENK induction in rostral NCM could be associated with a higher efficacy of the synapses between neuron B and neuron D. This might then explain why long-term electrophysiological habituation of caudal NCM (Chew et al. 1995,1996; Stripling et al. 1997) appears to correlate with ZENK expression in rostral NCM (Mello et al. 1992; Mello and Ribeiro 1998; Ribeiro et al. 1998; Ribeiro 2000).

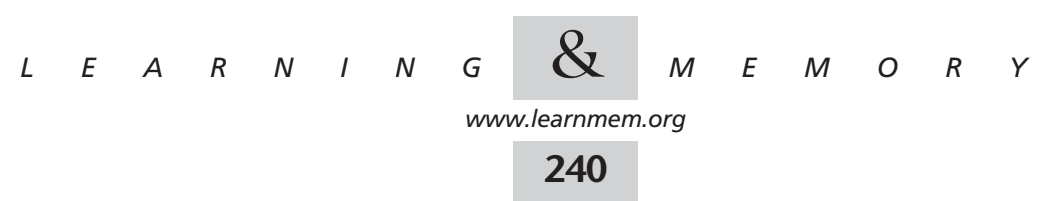


To explain the decrement in electrophysiological activity in caudal NCM according to this alternative scenario, one would need to postulate the participation of an intervening inhibitory relay within the circuit. However, when we stained NCM sections with an antibody against the GABAergic marker, GAD-67, we observed no labeling either in NCM or in CMHV, whereas a low-to-moderate number of highly labeled cells appear in field L2a (Ribeiro 2000). Although preliminary, this result suggests that most NCM neurons are likely to be excitatory, and that inhibitory actions on the caudalmost portions of NCM are indirect, possibly through field L2a. Inhibitory neurons within field L have been proposed to play a role in the exquisite frequency tuning of field L2a neurons (Leppelsack and Vogt 1976; Muller and Leppelsack 1985; Muller and Scheich 1988), and immunohistochemical studies of nonsongbird avian species have shown that $\sim 10 \%$ of field $\mathrm{L}$ neurons are GABAergic (Muller 1988). An example of a hypothetical connectivity scheme that includes a GABAergic projection from field L2a to caudal NCM is shown in Figure 5. According to this model, enhancement of synaptic efficacies in rostral NCM would act to decrease neuronal responsiveness in caudal NCM, by means of an inhibitory loop through field L2a.

These alternative views on the relationship between ZENK expression and electrophysiological habituation in NCM should be put to test in at least three fronts. Tracttracing neuroanatomical studies must be performed to learn in detail about the microcircuitry within NCM. Equally needed are pharmacological studies to explore the role of GABAergic field L neurons in NCM's habituation to song. Finally, a careful search for LTP should be performed in rostral NCM, using orthodromic stimulation from field L2a or the thalamic nucleus ovoidalis. We believe these research directions should contribute significantly to our understanding of the basic mechanisms involved in the auditory memorization of birdsong.

\section{ACKNOWLEDGMENTS}

We thank Constantine Pavlides and two anonymous reviewers for their insightful criticism of the manuscript. This work was supported by a Kluge Fellowship (to S.R.) and the NIDCD (grant 02853 to C.V.M.).

\section{REFERENCES}

Abraham, W.C., Mason, S.E., Demmer, J., Williams, J.M., Richardson, C.L., Tate, W.P., Lawlor, P.A., and Dragunow, M. 1993. Correlations between immediate early gene induction and the persistence of long-term potentiation.Neuroscience 56: 717-727.

Aston-Jones, G. and Bloom, F.E. 1981a. Activity of norepinephrine-containing locus coeruleus neurons in behaving rats anticipates fluctuations in the sleep-waking cycle. J. Neurosci.1: 876886.

. 1981b. Norepinephrine-containing locus coeruleus neurons in behaving rats exhibit pronounced responses to non-noxious environmental stimuli. J. Neurosci.1: 887-900.
Bolhuis, J.J., Zijlstra, G.G., den Boer-Visser, A.M., and Van Der Zee, E.A. 2000. Localized neuronal activation in the zebra finch brain is related to the strength of song learning. Proc. Natl. Acad. Sci. 97: 2282-2285

Bottjer, S.W., Halsema, K.A., Brown, S.A., and Miesner, E.A. 1989. Axonal connections of a forebrain nucleus involved with vocal learning in zebra finches. J. Comp. Neurol. 279: 312-326.

Bottjer, S.W., Miesner, E.A., and Arnold, A.P. 1984. Forebrain lesions disrupt development but not maintenance of song in passerine birds. Science 224: 901-903.

Bradley, P.M., Burns, B.D., King, T.M., and Webb, A.C. 1993. NMDA-receptors and potentiation in an area of avian brain essential for learning. Neuroreport 5: 313-316.

Bradley, P.M., Burns, B.D., and Webb, A.C. 1995. Noradrenaline and potentiation in the chick brain slice. Neuroreport 6: 1501-1504.

Butler, A. and Hodos, W. 1996. Comparative vertebrate anatomy: Evolution and adaptation. Wiley-Liss Press, New York, NY.

Chew, S.J., Mello, C., Nottebohm, F., Jarvis, E., and Vicario, D.S. 1995. Decrements in auditory responses to a repeated conspecific song are long-lasting and require two periods of protein synthesis in the songbird forebrain. Proc. Natl. Acad. Sci. 92: 3406-3410.

Chew, S.J., Vicario, D.S., and Nottebohm, F. 1996. A large-capacity memory system that recognizes the calls and songs of individual birds. Proc. Natl. Acad. Sci. 93: 1950-1955.

Christy, B.A., Lau, L.F., and Nathans, D. 1988. A gene activated in mouse 3T3 cells by serum growth factors encodes a protein with "zinc finger" sequences. Proc. Natl. Acad. Sci. 85: 7857-7861.

Christy, B. and Nathans, D. 1989. DNA binding site of the growth factor-inducible protein Zif268. Proc. Natl. Acad. Sci. 86: 8737-8741.

Cirelli, C., Pompeiano, M., and Tononi, G. 1996. Neuronal gene expression in the waking state: A role for the locus coeruleus. Science 274: 1211-1215

Cole, A.J., Abu-Shakra, S., Saffen, D.W., Baraban, J.M., and Worley, P.F. 1990. Rapid rise in transcription factor mRNAs in rat brain after electroshock-induced seizures. J. Neurochem. 55: 1920-1927.

Cole, A.J., Saffen, D.W., Baraban, J.M., and Worley, P.F. 1989. Rapid increase of an immediate early gene messenger RNA in hippocampal neurons by synaptic NMDA receptor activation. Nature 34: 474-476.

Doupe, A.J. 1997. Song- and order-selective neurons in the songbird anterior forebrain and their emergence during vocal development. $J$. Neurosci. 17: 1147-1167.

Doupe, A.J. and Konishi, M. 1991. Song-selective auditory circuits in the vocal control system of the zebra finch. Proc. Natl. Acad. Sci. 88: 11339-11343.

Everitt, B.J., Robbins, T.W., Gaskin, M., and Fray, P.J. 1983. The effects of lesions to ascending noradrenergic neurons on discrimination learning and performance in the rat. Neuroscience 10: 397-410.

Goelet, P., Castellucci, V.F., Schacher, S., and Kandel, E.R. 1986. The long and short of long-term memory - a molecular framework. Nature 322: 419-422.

Gupta, M.P., Gupta, M., Zak, R., and Sukhatme, V.P. 1991. Egr-1, a serum-inducible zinc finger protein, regulates transcription of the rat cardiac $\alpha$-myosin heavy chain gene. J. Biol. Chem. 266: 12813-12816.

Hopkins, W.F. and Johnston, D. 1984. Frequency-dependent noradrenergic modulation of long-term potentiation in the hippocampus. Science 226: 350-352.

Jarvis, E.D. and Mello, C.V. 2000. Molecular mapping of brain areas involved in parrot vocal communication. J. Comp. Neurol. 419: 1-31.

Jarvis, E.D., Mello, C.V., and Nottebohm, F. 1995. Associative learning and stimulus novelty influence the song-induced expression of an immediate early gene in the canary forebrain. Learn. Mem. 2: 62-80.

Jarvis, E.D., Ribeiro, S., Vielliard, J., da Silva, M.L., Ventura, D., and Mello, C.V. 2000. Behaviorally-driven gene expression reveals hummingbird brain vocal nuclei. Nature 406: 628-632.

Jarvis, E.D., Schwabl H., Ribeiro, S., and Mello, C.V. 1997. Brain gene regulation by territorial singing behavior in freely ranging songbirds Neuroreport 8: 2073-2077.

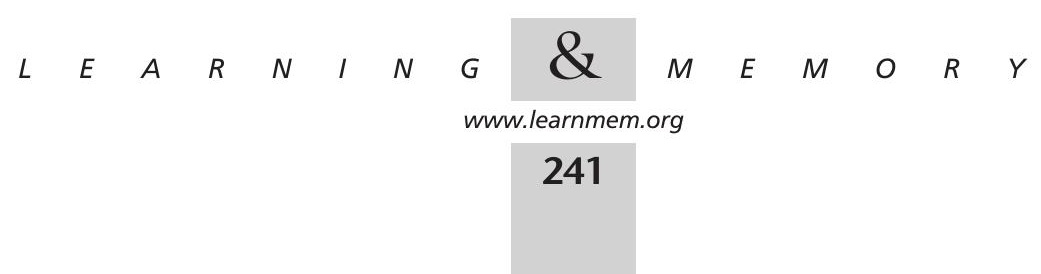


Karten, H.J. 1991. Homology and evolutionary origins of the 'neocortex'. Brain Behav. Evol. 38: 264-272.

-1997. Evolutionary developmental biology meets the brain: the origins of mammalian cortex. Proc. Natl. Acad. Sci. 94: 2800-2804.

Kobayashi, R.M., Palkovits, M., Jacobowitz, D.M., and Kopin, I.J. 1975. Biochemical mapping of the noradrenergic projection from the locus coeruleus. A model for studies of brain neuronal pathways. Neurology 25: 223-233.

Kruse, A., Stripling, R., and Clayton, D. 2000. Minimal experience required for immediate-early gene induction in zebra finch neostriatum. Neurobiol. Learn. Mem. In press.

Lemaire, P., Revelant, O., Bravo, R., and Charnay, P. 1988. Two mouse genes encoding potential transcription factors with identical DNA-binding domains are activated by growth factors in cultured cells. Proc. Natl. Acad. Sci. 85: 4691-4695.

Leppelsack, H.J. and Vogt, M. 1976. Responses of auditory neurons in the forebrain of a songbird to stimulation with species-specific sounds. $J$. Comp. Physiol. 107: 263-274.

Li, X-C., Jarvis, E.D., Alvarez-Borda, B., Lim, D.A., and Nottebohm, F. 2000. A relationship between behavior, neurotrophin expression, and new neuron survival. Proc. Natl. Acad. Sci. 97: 8584-8589.

Livingston, F.S. and Mooney, R. 1997. Development of intrinsic and synaptic properties in a forebrain nucleus essential to avian song learning. J. Neurosci. 17: 8997-9009.

Margoliash, D. 1983. Acoustic parameters underlying the responses of song-specific neurons in the white-crowned sparrow. J. Neurosci. 3: 1039-1057.

- 1986. Preference for autogenous song by auditory neurons in a song system nucleus of the white-crowned sparrow. J. Neurosci. 6: $1643-1661$.

- 1997. Functional organization of forebrain pathways for song production and perception. J. Neurobiol. 33: 671-693.

Margoliash, D. and Fortune, E.S. 1992. Temporal and harmonic combination-sensitive neurons in the zebra finch's HVc. J. Neurosci. 12: 4309-4326.

Mello, C.V. 1993. Analysis of immediate-early gene expression in the songbird brain following song presentation. Ph.D. Thesis, The Rockefeller University.

Mello, C.V. and Clayton, D.F. 1994. Song-induced ZENK gene expression in auditory pathways of songbird brain and its relation to the song control system. J. Neurosci. 14: 6652-6666.

Mello, C.V., Nottebohm, F., and Clayton, D. 1995. Repeated exposure to one song leads to a rapid and persistent decline in an immediate early gene's response to that song in zebra finch telencephalon. J. Neurosci. 15: 6919-6925.

Mello, C.V., Pinaud, R., and Ribeiro, S. 1998. Noradrenergic system of the zebra finch brain: immunocytochemical study of dopamine- $\beta$-hydroxylase. J. Comp. Neurol. 400: 207-228.

Mello, C.V. and Ribeiro, S. 1998. ZENK protein regulation by song in the brain of songbirds. J. Comp. Neurol. 393: 426-438.

Mello, C.V., Vates, G.E., Okuhata, S., and Nottebohm, F. 1998. Descending auditory pathways in the adult male zebra finch (Taeniopygia guttata). J. Comp. Neurol. 395: 137-160.

Mello, C.V., Vicario, D.S., and Clayton, D.F. 1992. Song presentation induces gene expression in the songbird forebrain. Proc. Natl. Acad. Sci. 89: 6818-6822.

Milbrandt, J. 1987. A nerve growth factor-induced gene encodes a possible transcriptional regulatory factor. Science 238: 797-799.

Muller, C.M. 1988. Distribution of GABAergic perikarya and terminals in the centers of the higher auditory pathway of the chicken. Cell Tissue Res. 252: 99-106.

Muller, C.M. and Leppelsack, H.J. 1985. Feature extraction and tonotopic organization in the avian auditory forebrain. Exp. Brain Res. 59: 587-599.

Muller, C.M. and Scheich, H. 1988. Contribution of GABAergic inhibition to the response characteristics of auditory units in the avian forebrain. J. Neurophysiol. 59: 1673-1689.

Nastiuk, K.L., Mello, C.V., George, J.M., and Clayton, D.F. 1994. Immediate-early gene responses in the avian song control system: cloning and expression analysis of the canary c-jun cDNA. Mol. Brain Res. 27: 299-309.

Nguyen, P.V., Abel, T., and Kandel, E.R. 1994. Requirement of a critical period of transcription for induction of a late phase of LTP. Science 265: 1104-1107.

Nottebohm, F., Kelley, D.B., and Paton, J.A. 1982. Connections of vocal control nuclei in the canary telencephalon. J. Comp. Neurol. 207: 344-357.

Nottebohm, F., Stokes, T.M., and Leonard, C.M. 1976. Central control of song in the canary, Serinus canarius. J. Comp. Neurol. 165: 457-486.

Petersohn, D., Schoch, S., Brinkmann, D.R., and Thiel, G. 1995. The human synapsin II gene promoter. Possible role for the transcription factor zif268/egr-1, polyoma enhancer activator 3, and AP2. J. Biol. Chem. 270: 24361-24369.

Ribeiro, S. 2000. Song, sleep, and the slow evolution of thoughts: Gene expression studies on brain representation. Ph.D. Thesis, The Rockefeller University.

Ribeiro, S., Cecchi, G.A., Magnasco, M.O., and Mello, C.V. 1998. Toward a song code: evidence for a syllabic representation in the canary brain. Neuron 21: 359-371.

Ribeiro, S., Pinaud, R., and Mello, C.V. 1999. Noradrenergic modulation of song-induced ZENK expression in the zebra finch brain. In Proceedings of the Society for Neuroscience 29th annual meeting, Miami, pp. 865.

Roberts, L.A., Higgins, M.J., O'Shaughnessy, C.T., Stone, T.W., and Morris, B.J. 1996. Changes in hippocampal gene expression associated with the induction of long-term potentiation. Mol. Brain Res. 42: 123-127.

Scharff, C. and Nottebohm, F. 1991. A comparative study of the behavioral deficits following lesions of various parts of the zebra finch song system: implications for vocal learning. J. Neurosci. 11: 2896-2913.

Schmidt, M.F. and Konishi, M. 1998. Gating of auditory responses in the vocal control system of awake songbirds. Nat. Neurosci. 1: 513-518.

Shapiro, E. and Wieraszko, A. 1996. Comparative, in vitro, studies of hippocampal tissue from homing and non-homing pigeon. Brain Res. 725: 199-206

Sheng, M. and Greenberg, M.E. 1990. The regulation and function of c-fos and other immediate early genes in the nervous system. Neuron 4: $477-485$.

Sheng, M., McFadden, G., and Greenberg, M.E. 1990. Membrane depolarization and calcium induce c-fos transcription via phosphorylation of transcription factor CREB. Neuron 4: 571-582.

Shors, T.J. and Matzel, L.D. 1997. Long-term potentiation: What's learning got to do with it? Behav. Brain Sci. 20: 597-614.

Sohrabji, F., Nordeen, E.J., and Nordeen, K.W. 1990. Selective impairment of song learning following lesions of a forebrain nucleus in the juvenile zebra finch. Behav. Neural Biol. 53: 51-63.

Stripling, R., Volman, S.F., and Clayton, D.F. 1997. Response modulation in the zebra finch neostriatum: relationship to nuclear gene regulation. $J$. Neurosci. 17: 3883-3893.

Sukhatme, V.P., Cao, X.M., Chang, L.C., Tsai-Morris, C.H., Stamenkovich, D., Ferreira, P.C., Cohen, D.R., Edwards, S.A., Shows, T.B., Curran, T., et al. 1988. A zinc finger-encoding gene coregulated with c-fos during growth and differentiation, and after cellular depolarization. Cell 53: 37-43.

Sullivan, R.M., Wilson, D.A., and Leon, M. 1989. Norepinephrine and learning-induced plasticity in infant rat olfactory system. J. Neurosci. 9: 3998-4006.

Sutter, M.L. and Margoliash, D. 1994. Global synchronous response to autogenous song in zebra finch HVc. J. Neurophysiol. 72: 2105-2123.

Swanson, L.W. and Hartman, B.K. 1975. The central adrenergic system. An immunofluorescence study of the location of cell bodies and their efferent connections in the rat utilizing dopamine- $\beta$-hydroxylase as a marker. J. Comp. Neurol. 163: 467-505.

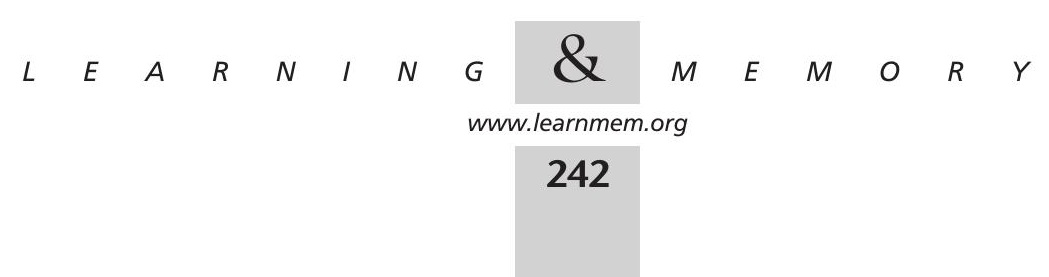


Thiel, G., Schoch, S., and Petersohn, D. 1994. Regulation of synapsin I gene expression by the zinc finger transcription factor zif268/egr-1. $J$. Biol. Chem. 269: 15294-15301.

Vates, G.E., Broome, B.M., Mello, C.V., and Nottebohm, F. 1996. Auditory pathways of caudal telencephalon and their relation to the song system of adult male zebra finches. J. Comp. Neurol. 366: 613-642.

Vicario, D.S. and Nottebohm, F. 1988. Organization of the zebra finch song control system: I. Representation of syringeal muscles in the hypoglossal nucleus. J. Comp. Neurol. 271: 346-354.

Williams, H. and Nottebohm, F. 1985. Auditory responses in avian vocal motor neurons: a motor theory for song perception in birds. Science 229: 279-282.

Wisden, W., Errington, M.L., Williams, S., Dunnett, S.B., Waters, C., Hitchcock, D., Evan, G., Bliss, T.V.P., and Hunt, S.P. 1990. Differential expression of immediate early genes in the hippocampus and spinal cord. Neuron 4: 603-614.

Worley, P.F., Bhat, R.V., Baraban, J.M., Erickson, C.A., McNaughton, B.L., and Barnes, C.A. 1993. Thresholds for synaptic activation of transcription factors in hippocampus - correlation with long-term enhancement. J. Neurosci. 13: 4776-4786. 


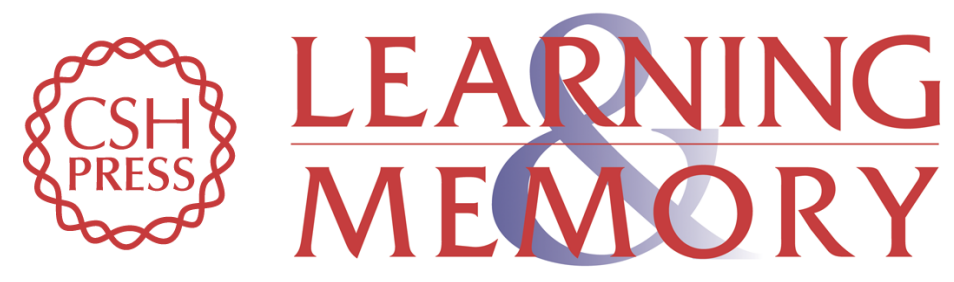

\section{Gene Expression and Synaptic Plasticity in the Auditory Forebrain of Songbirds}

S. Ribeiro and C.V. Mello

Learn. Mem. 2000, 7:

Access the most recent version at doi:10.1101//m.34400

References This article cites 71 articles, 34 of which can be accessed free at:

http://learnmem.cshlp.org/content/7/5/235.full.html\#ref-list-1

License

Email Alerting Receive free email alerts when new articles cite this article - sign up in the box at the Service top right corner of the article or click here. 